\title{
Esophageal Squamous Cell Carcinoma by AJCC v7 Stage
}

National Cancer Institute

\section{Source}

National Cancer Institute. Esophageal Squamous Cell Carcinoma by A/CC v7 Stage. NCI Thesaurus. Code C133442.

A term that refers to the staging of esophageal squamous cell carcinoma according to the American Joint Committee on Cancer, 7th edition. 